\title{
REAL-TIME ATTENDANCE AND ESTIMATION OF PERFORMANCE USING BUSINESS INTELLIGENCE
}

\author{
Manoj Pandita ${ }^{1}$, Pallavi Shinde ${ }^{2}$, Dnyanada Shirsat ${ }^{3}$, Seema Yadav $^{4}$

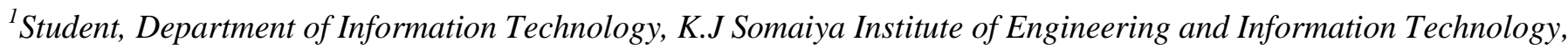 \\ University of Mumbai, Maharashtra, India \\ ${ }^{2}$ Student, Department of Information Technology, K.J Somaiya Institute of Engineering and Information Technology, \\ University of Mumbai, Maharashtra, India \\ ${ }^{3}$ Student, Department of Information Technology, K.J Somaiya Institute of Engineering and Information Technology, \\ University of Mumbai, Maharashtra, India \\ ${ }^{4}$ Assistant Professor, Department of Information Technology, K.J Somaiya Institute of Engineering and Information \\ Technology, University of Mumbai, Maharashtra, India
}

\begin{abstract}
The manual process of filling and submission of the Outdoor Duty Forms is very common today. Also there are many alternatives available for automated process of remote attendance and data analysis. But there is no solution yet that provides the integrated solution for automation of all these process. We therefore came with the concept of an application that provides these services. This application is about automated process of Outdoor duty forms, remote attendance, submission of sales and marketing data and its analysis. The application will be designed for corporate usage. A database system will be maintained regarding the submission of data and this data will be used for further analysis and intelligent results.
\end{abstract}

Keywords: ODForms (Outdoor Duty Forms), BI (Business Intelligence), RFID (Radio Frequency Identification), RTO (Regional Transport Office), KPI (Key Point Indicators).

\section{INTRODUCTION}

The manual process of ODForms is very common today. There are many software available for attendance procedure as well for sales and marketing data work. The manual process of ODForms is like manual filling of forms and submission, register entries etc. and for that of remote attendance the mobile applications, biometric checking devices etc. are available. But there no such system that provide the functionalities of all these processes in a simple automated form. Thus an application that provides all these functionalities is being introduced.

This application is about to make it easy for the employees working outdoors to mark their attendance, working hours and to get approval from the seniors. The general functionalities of this application include marking attendance in working hours, mobilizing the manual process, updating database with valuable employee information. It helps the organization to track the employee location. Outdoor duties are done to gather on sight information about the client and to inspect the client side problems. They are activities performed by employees outside company at client side. Manual filling of OD faces problem in reporting. The current process for outdoor duties is manual. That is the working hours are wasted in the process of form filling, analyzing the forms, approval for forms updating databases. Filling manual form takes time and getting it approved is another issue. Manual OD form filling does not ensures whether the employee is actually performing the duty as specified in his OD Form. Also the attendance of the employee can be marked remotely by logging into his id.

Also it takes a lot of time for marketing people to meet the clients and make them fill the survey form or to manually gather the details of the client and then update them in the company database later. Also the client feels tired or frustrated to fill the manual form of his/her details. The application will help in finding out the potential customers for the company. In the marketing department the information gathered by the application will be used to study the growth of product. Also the potential customers identified by the sales team will be provided detailed information about the working of the application and its use in their company. These are the valuable details that are of great value to the company, so they should not be misplaced or lost under any circumstances.

\section{EXISTING SYSTEMS}

\subsection{Manual Attendance}

In Manual Attendance an employee of an organization has to come to office to mark his attendance. The drawback of marking the attendance manually when an employee goes for his outdoor duty is that he has to come to the office to get his attendance marked which in turn results in the wastage of productive time of the employee. Also if the record book in which the attendance is marked is lost the complete data is lost. 


\subsection{Manual ODForms}

If an employee has an Outdoor duty he has to get the letter sanctioned for the approval. The employee has to be present in the office on that day to get his approval. The all process sometimes can be time consuming .this results in the loss of precious time of the employee. Due to the process of manual od forms it's difficult to judge whether the employee is really working on the leaves that the employee is assigned. The job completion cannot be determined.

\subsection{Mobile Attendance}

In mobile attendance ${ }^{[1][2][3]}$ every student is provided with a id card which has a magnetic chip that has the details of the student. Each id card is assigned a unique serial number. The sensor on the mobile device scans the magnetic chip of the id card and marks the attendance of the unique serial number. The drawback of using mobile attendance is proxy attendance i.e. anyone can mark the attendance by getting the id card scanned on the mobile device without the presence of the student.

\subsection{Biometric Attendance}

In biometric attendance ${ }^{[4]}$ we recognize people's unique physiological characteristics like persons unique fingerprints iris voice recognition. The characteristics on which we are authenticating the user are stored first in the database and then are matched when the user logins. If the pattern matches the attendance is marked.

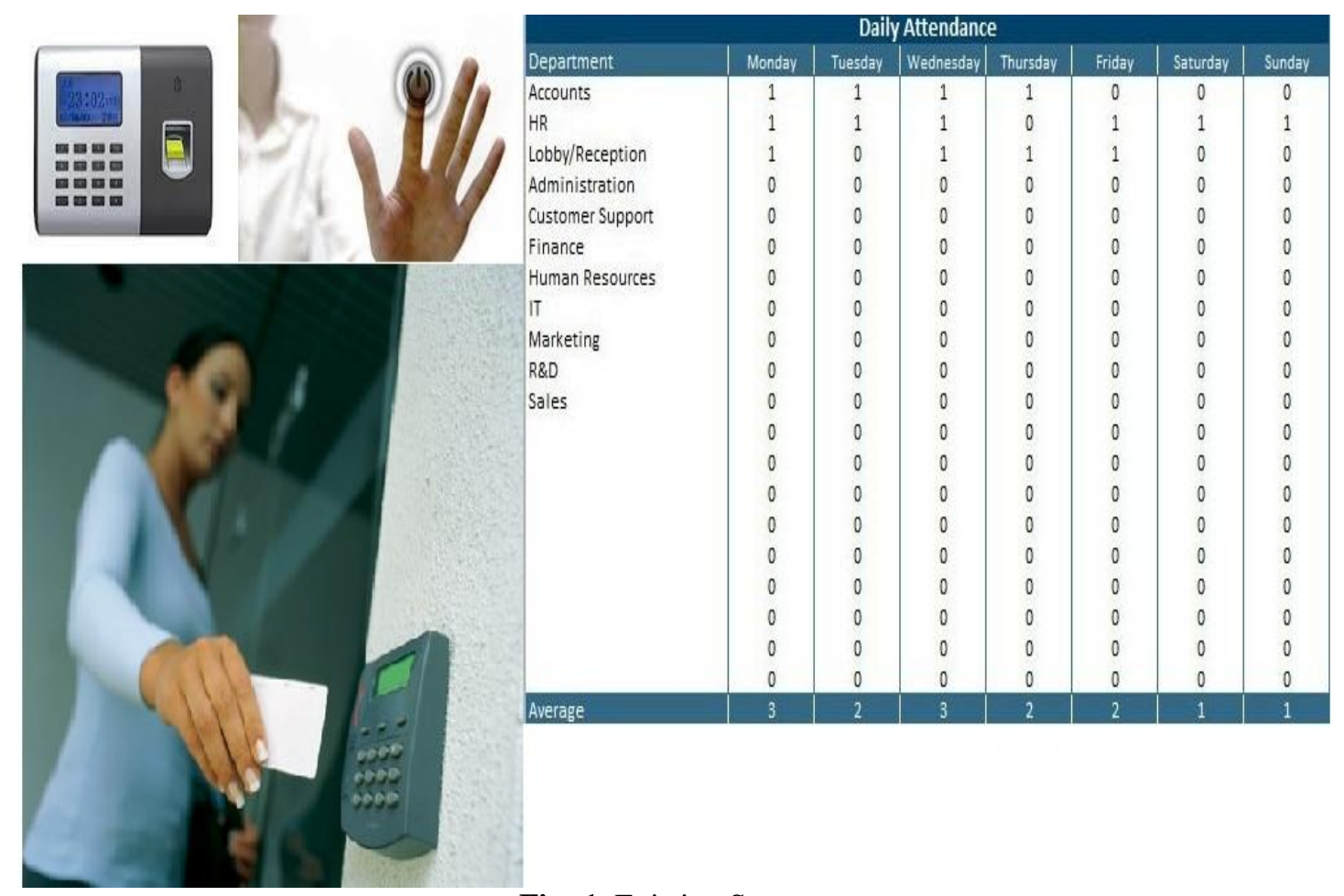

Fig -1: Existing Systems

\section{COMPARISON}

Table -1: Comparison (Proposed system and existing system)

\begin{tabular}{|c|c|c|}
\hline Parameters & Proposed System & Existing System \\
\hline $\begin{array}{l}\text { Remote } \\
\text { Attendance }\end{array}$ & $\begin{array}{l}\text { It can be submitted } \\
\text { remotely, low cost, } \\
\text { easy maintenance; } \\
\text { attendance will be } \\
\text { submitted by } \\
\text { capturing image, } \\
\text { location and IMEI } \\
\text { code. }\end{array}$ & $\begin{array}{l}\text { Attendance is } \\
\text { submitted using } \\
\text { biometrics, } \\
\text { RFID }^{[2][3]} \text { etc. high } \\
\text { hardware cost and } \\
\text { hence difficult } \\
\text { maintenance. }\end{array}$ \\
\hline $\begin{array}{l}\text { Outdoor Duty } \\
\text { Forms }\end{array}$ & $\begin{array}{l}\text { Mobilized } \\
\text { submission } \\
\text { forms }\end{array}$ & $\begin{array}{l}\text { Manual } \\
\text { submission } \\
\text { forms. }\end{array}$ \\
\hline
\end{tabular}

\begin{tabular}{|l|l|l|}
\hline & $\begin{array}{l}\text { estimation of } \\
\text { employee } \\
\text { performance on } \\
\text { OD. }\end{array}$ & \\
\hline $\begin{array}{l}\text { Sales and } \\
\text { Marketing }\end{array}$ & $\begin{array}{l}\text { Remotely submit } \\
\text { client data and } \\
\text { contacts, analysis } \\
\text { of data to calculate } \\
\text { profit and loss. }\end{array}$ & $\begin{array}{l}\text { Submission of data } \\
\text { at one destination } \\
\text { only. }\end{array}$ \\
\hline KPI & $\begin{array}{l}\text { Estimation of } \\
\text { performance of } \\
\text { employees, budget, } \\
\text { profit, loss of } \\
\text { company all in one } \\
\text { application. Cost of } \\
\text { installation is low. }\end{array}$ & $\begin{array}{l}\text { Different software } \\
\text { for each analysis. } \\
\text { is high. }\end{array}$ \\
\hline
\end{tabular}




\section{PROPOSED SYSTEM}

As shown in figure 2, in our proposed system the employee will login into the application through an id and password. For each employee different id and password will be generated. After successful logging into the application the employee will need to click a picture of him and submit it. The location of the employee will be tracked. When the employee submits the picture it's matched with the image that is stored in the database for that particular employee. If the images match the attendance is marked successfully. For getting the approval of the outdoor duty form the employee fills the details in the outdoor duty form and submits it. The project manager gets a notification on a pending request for approval. The manager can approve or reject the outdoor duty form. The employee can check the status of his form.

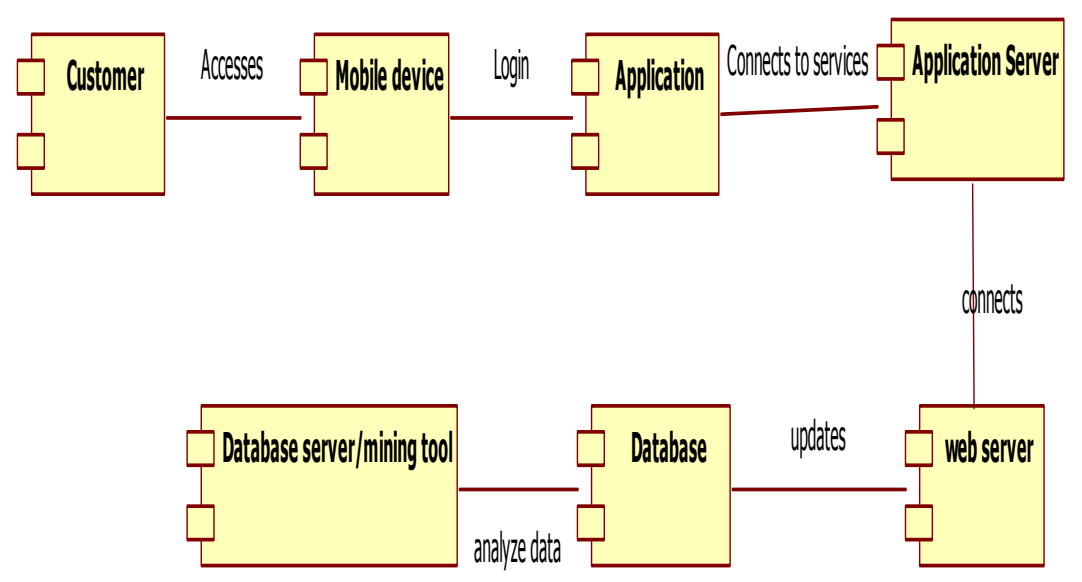

Fig -2: Block Diagram

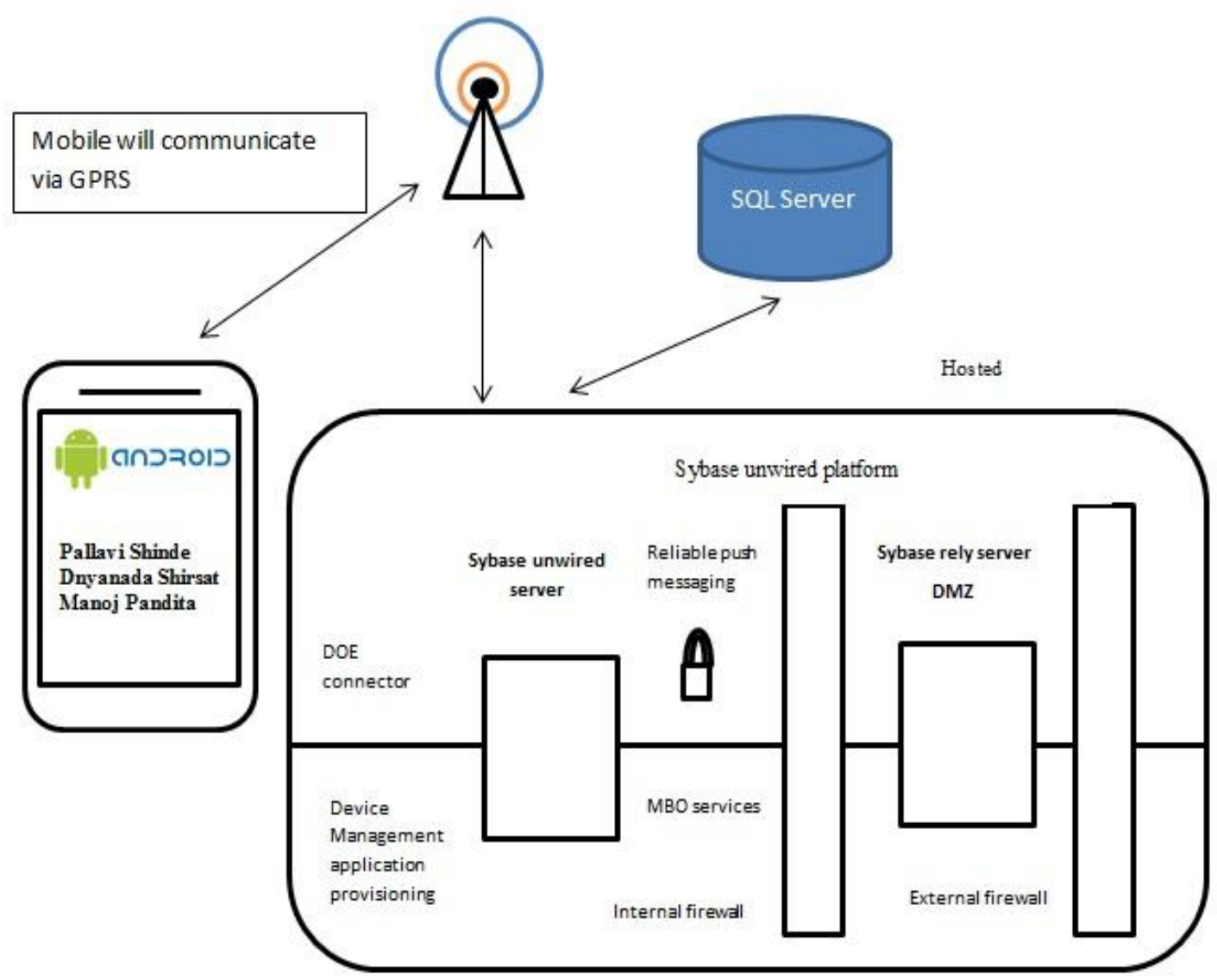

Fig -3: System Architecture Diagram 


\section{ALGORITHMS}

\subsection{For OD Form}

5.1.1 Create a root node Designation with three child Employee, Manager, HR.

5.1.2 Each child represents a sub-node Attendance.

5.1.3 Classify attendance as low or high on basis of maximum leave criteria and further split them for OD analysis.

5.1.4 Based on the designation, attendance and the number of OD's previously approved decide whether to approve the OD or not.

\subsection{The Regression Algorithm:}

Regression algorithm will be used to make out the overall profit and loss as per the client deals made and the deals cancelled.

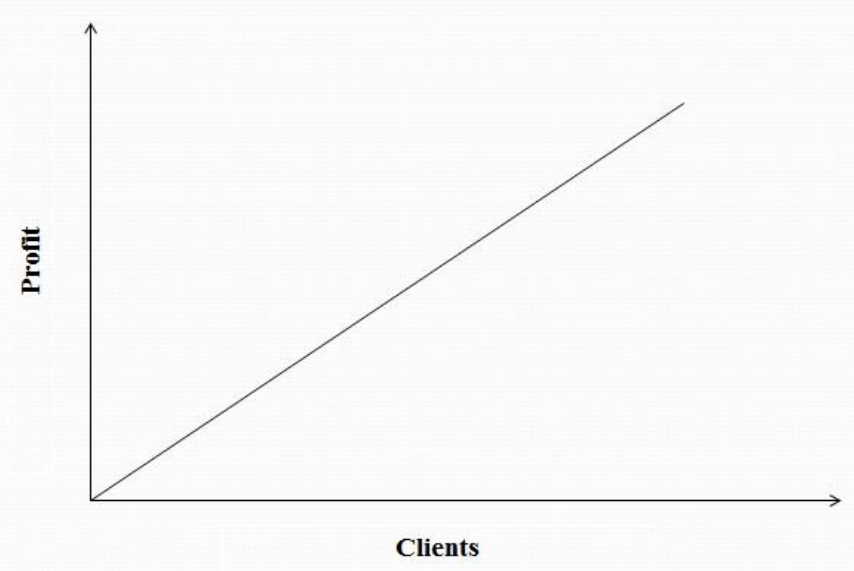

Fig -4: Graph of Linear Regression Algorithm for Profit/Loss

\subsection{Feedback Algorithm:}

A simple count will be defined that will store the positive and negative ratings from feedback. Based on this count the overall performance of the sales/marketing team will be made out.

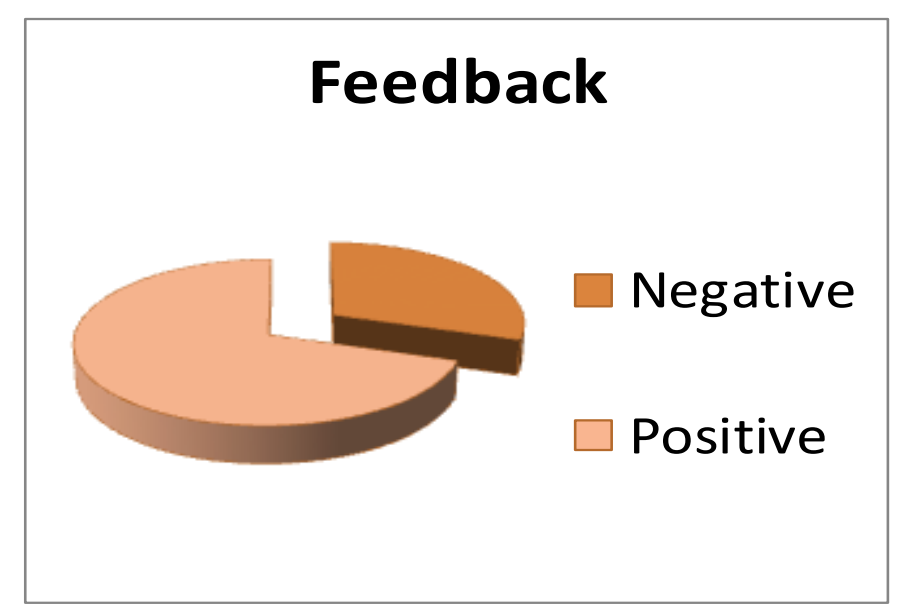

Fig -5: Pie Chart for Negative/Positive Feedback from Sales and Marketing.

\section{APPLICATIONS}

\subsection{Medical History Retrieval}

Usually when a patient visits for medical checkup he/she is asked to submit the historical reports regarding his medical checkup. In this case instead this application can serve best. The doctor simply needs to capture an image of patient and the historical data regarding the patient's medical will be directed from the database.

\subsection{Sales and Marketing}

When a sales or marketing person deals with their customers, they can save the customers data and information regarding deal directly through the application.

\subsection{Medical representatives}

Medical representatives need to go on outdoor duties at different places. They can thus update the information regarding medicines, supplies etc. on the way.

\subsection{RTO:}

Whenever any accidents or road rash occurs a challan(receipt) is assigned. There is no storage of these records in databases. Using the application this drawback can be covered. The police simply needs to capture image of the challan (receipt) and submit to the database. So next time if any incident occurs the police can simply retrieve the data by just clicking his image and matching it in database. Also if the person's traffic crime crosses a certain number he can be given a warning as well as in some cases license can be cancelled.

\section{ADVANTAGES}

This application integrates the functioning of the modules which will be automated namely remote attendance, Outdoor duty form submission and analysis of sales and marketing data. Thus an overall application which will provide the three basic operations at one door step. 


\section{USER INTERFACE}

\subsection{Remote Attendance}

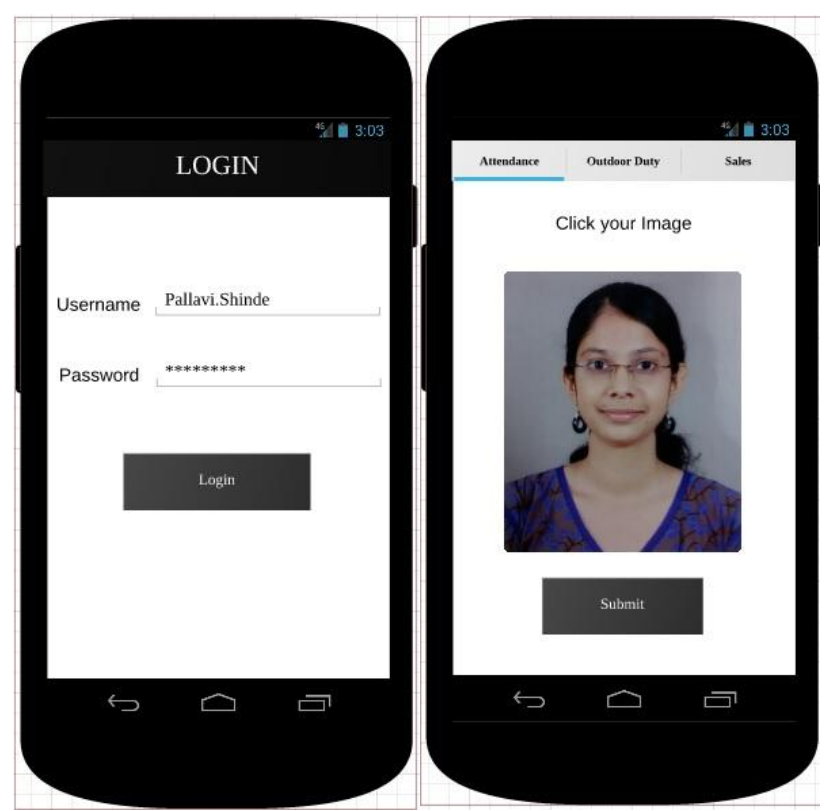

Fig -6: Login and Attendance submission

\subsection{ODForm Submission}

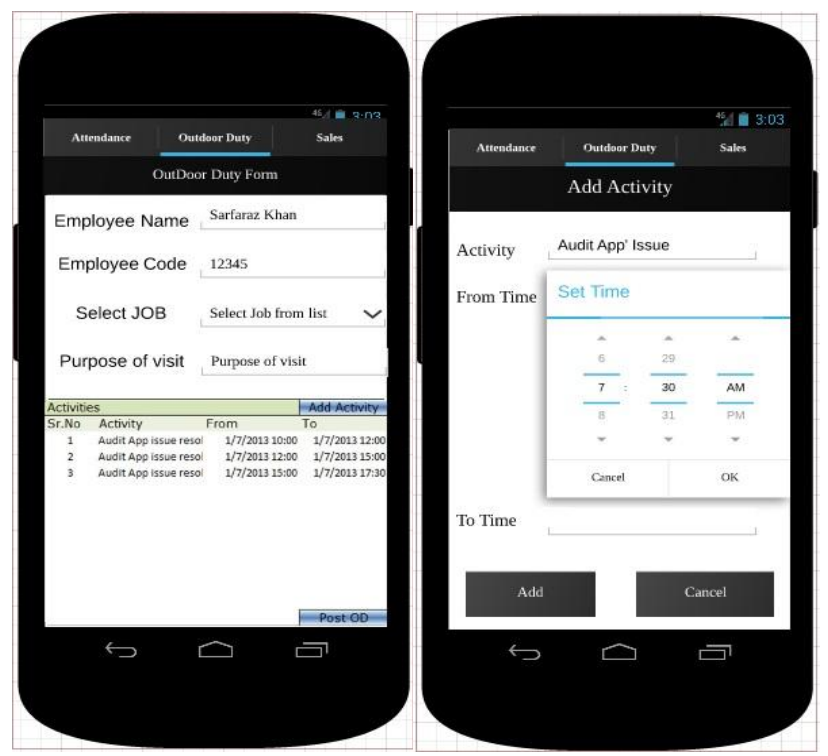

Fig -7: Outdoor Duty Form submission

\subsection{Sales and Marketing}

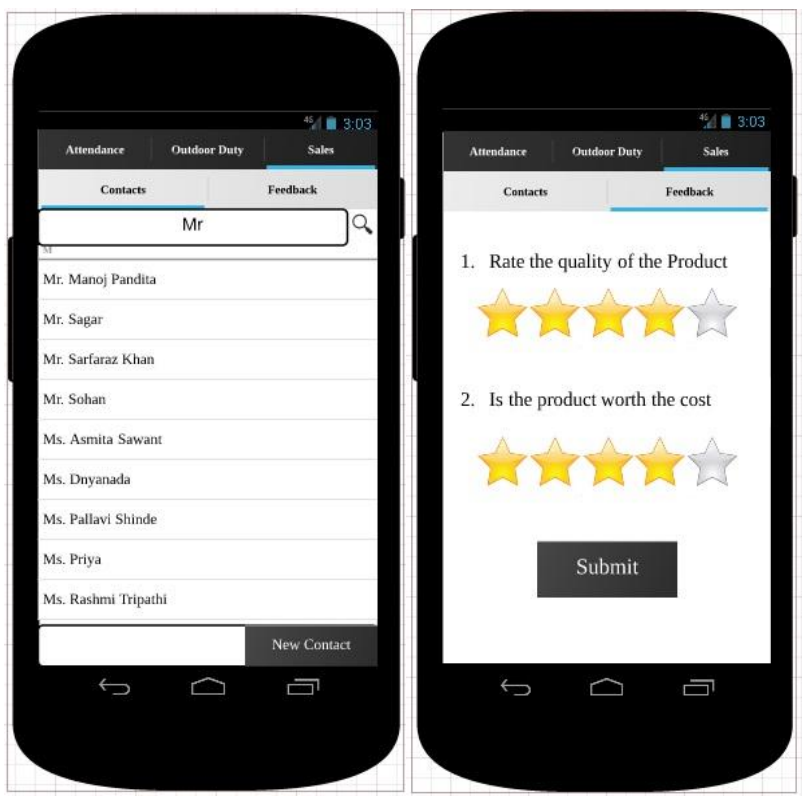

Fig -8: Sales and Marketing

\section{CHALLENGES}

\subsection{Compression \& De-Compression:}

The major challenges faced in remote attendance by capturing image are the compression and de-compression of image. Compressing the image and storing it in database is required to store image in database. But the real challenge is decompressing the image for identification.

\subsection{Network Problems}

The second major challenge faced is the network problems. If the internet connection is not available or the network is not available then remote attendance marking becomes a problem.

\section{CONCLUSION}

The proposed system is better than the existing systems with respect to time for updating database. This application integrates the three functionalities of Attendance, Salesmarketing and Outdoor duty forms which is not yet being developed elsewhere. The drawbacks of manual process have been eliminated. This application will save the productive time of the Employees and provide all services remotely through a single application. With the emerging new algorithms in future, this concept can be used in variety of sectors.

\section{ACKNOWLEDGEMENTS}

I would also take this opportunity to express a deep sense of gratitude to Mr. Sarfaraz Khan, Project Manager and Ms. Julie Varghese, HR, ServPRO Technologies Pvt Ltd. for their cordial support, valuable information and guidance in completing this task through various stages. I am grateful for their co-operation during the period of my course of the thesis. 


\section{REFERENCES}

[1] Shibata.H,"An attendance management system using mobile phones,'IEEE,Communications computers \& signal processing, Osaka, Japan, pp.590-592,August 2005.

[2] By Scott McLeod, By Allan Jones,"Should RFID be used to monitor students?,'ISTE(International society for technology in education), November 2006.

[3] Rajan Patel, Nimisha Patel, Mona Gajjar,'Online students' attendance monitoring system in classroom using using Radio Frequency Identification technology: A proposed system framework, International Journal of emerging technology and advanced engineering, vol. 2, issue 2, February 2012.

[4] Peter, U.E, Joe-Uzuegbu, C.K.A; Uzoechi. L; Opara, F.K, "Biometric-based Attendance System with remote real-time monitoring for tertiary institutions in developing countries," IEEE,Owerri, pp.18, November 2013.

[5] Mobility, SRF_FSD_V1, ServPRO Technologies Pvt Ltd, Mumbai.

[6] Roger S. Pressman, "Software Engineering - A practioners approach,"pp.215-260, $7^{\text {th }}$ Edition.

[7] Galit Shmueli, Nitin R. Patel, Peter C. Bruce,'Data Mining for Business Intelligence-Concepts, Techniques \& Applications in Microsoft Office Excel with XLMiner, Wiley-India Edition.

[8] Jiawei Han, Micheline Kamber, Jian Pei,'Data Mining," pp.279-323, $3^{\text {rd }}$ Edition 2011.

\section{BIOGRAPHIES}

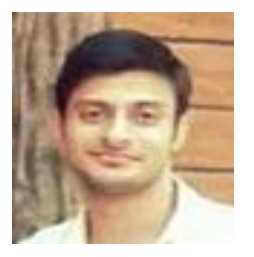

Manoj Pandita, student at K.J Somaiya Institute of Engineering and Information Technology, pursuing B.E degree in Information Technology.

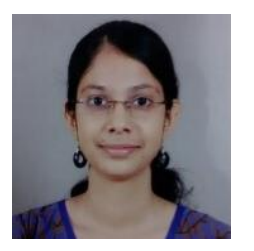

Pallavi Shinde, student at K.J Somaiya Institute of Engineering and Information Technology, pursuing B.E degree in Information Technology.

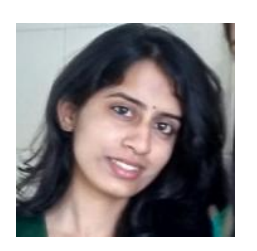

Dnyanada Shirsat, student at K.J Somaiya Institute of Engineering and Information Technology, pursuing B.E degree in Information Technology.

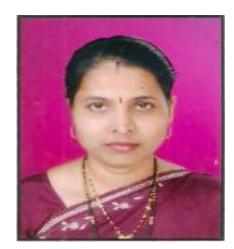

Prof. Seema Yadav, Assistant Professor at K.J Somaiya Institute of Engineering and Information Technology, Department of Information Technology. 